\title{
A NORMALIZAÇÃO DO IDOSO NA MÍDIA IMPRESSA: PROVOCAÇÕES FOUCAULTIANAS
}

\author{
Patricia Haertel Giusti*
}

\begin{abstract}
RESUMO
O envelhecimento tem sido uma temática de intensa discussão na atualidade. A mídia tem se encarregado de apresentar formas de ser e viver a velhice na contemporaneidade. O objetivo deste artigo é mapear acontecimentos discursivos que dão condições de possibilidade para emergência da velhice enquanto uma população. $\mathrm{O}$ estudo traz algumas ferramentas de uma análise discursiva sobre o processo de envelhecimento, a partir da utilização da mídia impressa, presente em reportagens de capa dos cadernos de saúde de dois jornais do Rio Grande do Sul, de 2004 a 2010. O campo teórico apresenta, especialmente, os estudos de Michel Foucault. Finalizamos problematizando uma velhice pautada pelo discurso da promoção da saúde, que aparece recorrentemente nas reportagens analisadas, e refletindo sobre todo investimento feito em prevenção para que a vida seja cada vez mais longa e melhor.
\end{abstract}

Palavras-chave: Saúde. Velhice. Mídia impressa. Estudos foucaultianos. Biopolítica.

\begin{abstract}
NORMALIZATION OF THE ELDERLY IN PRINT MEDIA: FOUCAULT'S PROVOCATIONS

Aging has been a theme of intense discussion in the present. The media has taken charge of presenting forms of being old and living in old age in contemporary times. The goal of this article is to map discursive events that make the emergency of old age as a population possible. The study brings some tools of a discursive analysis of the aging process, from the use of print media present in covers of reports on health from two newspapers of Rio Grande do Sul, from 2004 to 2010. The theoretical field is especially based on Michel Foucault's studies. We finish by contextualizing an old age guided by the discourse of health promotion that recurrently appears in the analyzed reports, and reflecting on all investment made for prevention in order to achieve a longer and better life.
\end{abstract}

Keywords: Health. Old age. Print media. Foucault studies. Biopolitics.

\footnotetext{
*Fisioterapeuta. Mestre em Saúde e Comportamento pela Universidade Católica de Pelotas (UCPel-RS). Doutoranda do Programa de Pós-Graduação em Educação em Ciências: Química da Vida e da Saúde pela Universidade Federal do Rio Grande (FURG-RS). Endereço institucional: Universidade Federal do Rio Grande, Av Itália, Km 8 -- Carreiros - Rio Grande-RS. phgiustia@gmail.com
} 


\section{Introdução}

O Brasil está envelhecendo! Estamos diante de uma transição epidemiológica na população do país onde vivemos. É diante deste cenário que podemos dizer que estar na terceira idade, falar de longevidade, buscar constantemente o auxílio da ciência médica tem sido algumas enunciações presentes na vida de milhares de pessoas que querem viver e compreender o processo de envelhecimento. Crianças, jovens, adultos, profissionais da saúde, seres humanos que diariamente escutam, produzem e reproduzem ações, seja na escola, em casa, nos consultórios ou em qualquer lugar em que estejam, o foco está voltado para o prolongamento da vida, para viver com qualidade de vida. Não há dúvida de que vivemos um tempo de intensificação das formas de enxergar a população de idosos.

Refletir sobre essa população requer saber que o velho, em tempos anteriores visto como indigente, não produtivo, surge na emergência de caracterizar os estágios da vida nas sociedades ocidentais, a partir do século XIX. De acordo com Silva (2008), a institucionalização da aposentadoria e os novos saberes médicos sobre o corpo do velho aparecem como os principais marcadores de ingresso neste novo ciclo.

Neste estudo apresentamos o recorte de uma tese de doutoramento que analisa o dispositivo da velhice no cenário contemporâneo, a partir de sua constituição na mídia impressa. Para este artigo traz-se, como questão principal, a tentativa de olhar para a História e perceber como se constituiu aquilo que hoje denominamos de terceira idade. Nesse sentido, aproximamo-nos do filósofo francês do século XX, Michel Foucault, para apresentar alguns traçados de uma história genealógica que coloca em pauta condições de possibilidade para emergência da velhice enquanto uma população.

Também entram em discussão algumas reportagens da mídia impressa sobre envelhecimento, presentes em cadernos de saúde de dois jornais, um de circulação regional da Metade Sul do Rio Grande do Sul e outro de circulação estadual, também do solo gaúcho, que possibilitarão uma interlocução com algumas temáticas do estudo foucaultiano.

Biopolítica, sociedade de normalização e população são alguns dos temas debatidos como ferramentas analíticas principais. Estes são colocados a funcionar a partir do momento em que os velhos são classificados como uma população e no momento em que há uma modificação de cenário que coloca em funcionamento ações de promoção de saúde, com o objetivo de garantir a longevidade.

Baseado nesse olhar sobre o envelhecimento é que as reportagens apresentam um velho que vive mais, e que, para isso, reconhece, em muitos momentos da sua vida, atitudes e ações que devem ser seguidas no intuito de chegar a essa faixa etária com qualidade. São estas problematizações que faremos a fim de verificar a que preço chegamos a tal idade, de que forma e com que responsabilidade individual e de Estado. São estes questionamentos que nos inquietam e nos colocam a pensar sobre aquilo que está anunciado para essa população. Iniciaremos, então, por alguns fragmentos genealógicos da velhice.

\section{Traçados Genealógicos da Velhice: provocações ao pensamento}

Apresentar alguns traçados da genealogia da velhice a partir de Michel Foucault requer dizer aqui que mostraremos uma história que não pretende buscar a origem, nem sequer desvendar a verdade que repousa em sua essência original, mas, sim, mostrar uma reunião de acontecimentos a partir de memórias locais, que possibilitam a constituição de um saber histórico e a utilização deste nas estratégias de ação apresentadas na atualidade.

O corpo do velho que, sob olhares atentos da medicina nos séculos XVIII e XIX, era tratado como o dos jovens, passa a ser analisado pelos saberes da geriatria e da gerontologia. Tais saberes emergem para estudar a velhice como problema clínico proveniente de um estado fisiológico específico. Embora saibamos que as preocupações com a longevidade, no sentido de possuirmos uma vida eterna, estivessem presentes nas observações da mitologia grega e em textos bíblicos, foi apenas no início do século XX que a geriatria surge como uma especialidade médica. De origem grega, a palavra geriatria (geras - velhice e iatria - cura) representa um ramo da medicina especializado no cuidado dos velhos. 
O médico Ignatz Nascher, através da escrita de um artigo em 1909 para o New York Medical Journal, parece ter sido o responsável pela introdução na comunidade médica do termo geriatria. Em seguida, a publicação de seu livro Geriactrics: the diseases of old age and their treatments, em 1914, pode ser entendida como uma das condições de possibilidade para o início desse novo campo de saber (PAPALÉO-NETTO, 1996).

Nessa época, o detalhamento do corpo do velho, através de traços de atrofia, degeneração, de mudanças visíveis na estrutura corporal do indivíduo, caracterizava o envelhecimento como uma patologia. A transformação do estado patológico em fisiológico exigiu, da área médica, o entendimento das condições "normais" do envelhecimento. Relatos anunciam que, desde os primeiros estudos médicos da geriatria, haveria dificuldades em diferenciar o estado patológico do estado "normal" na velhice (HABER, 1986). Este entendimento dos processos patológicos como próprios de uma velhice parece ter sido ponto em destaque dos primeiros especialistas no início do século XX.

O percurso histórico do saber sobre os velhos parece confundir-se com a própria história da medicina, que também nos séculos XVIII e XIX sofreu grandes modificações no modo como a doença era percebida pelos médicos. Antes de tais modificações, há uma demonstração de que o indivíduo, de alguma forma, praticava a medicina.

Dadas algumas modificações nesse cenário, a medicina, a partir do século XIX, através do exercício da anatomia patológica, enfatizou a busca pelos sinais da doença na superfície do corpo. Com o investimento no olhar sobre o corpo, os médicos romperam com o modelo secular da prática médica, que via a doença como produto da relação do indivíduo com forças divinas ou cósmicas. Esse novo modelo possibilitaria o reconhecimento do corpo envelhecido, uma vez que seria diferenciado do corpo jovem. É no fim do século XVIII, como nos mostra Foucault (2011), que a doença passa a ser um fenômeno da população. Ela traz a introdução de uma medicina que tem como função maior a higiene pública, conquistada através de organismos de coordenação dos tratamentos médicos, de centralização da informação, de normalização dos saberes e, ainda, através da realização de campanhas de higiene e medicalização da população.

O aparecimento da velhice como objeto de intervenção não ficou restrito ao corpo envelhecido, pois, associado a isso, o comportamento e as condições sociais dos velhos o categorizaram como uma entidade demográfica, ou seja, uma população. O saber especializado da geriatria também direcionou seus estudos para os hábitos, as práticas, as necessidades psicológicas e sociais dos velhos. Pautada pela conceituação foucaultiana de sociedade disciplinar (FOUCAULT, 2009), é possível dizer que a velhice surge como produção discursiva a partir da inserção dos sujeitos na série moderna de disciplinamento, sendo, sobretudo, o resultado do investimento do discurso médico sobre o corpo envelhecido.

Nessa mesma linha, é possível dizer que o surgimento dos idosos como uma categoria etária se dá também por uma forte constituição de poder que incide sobre a sociedade ocidental a partir do século XVIII. É na esteira de um poder disciplinar que os velhos são tomados como um problema social, sendo necessário criar estratégias de controle e docilização desses corpos.

Foucault (2009) localiza o momento histórico das disciplinas como o momento que nasce uma arte do corpo humano, arte esta que visa não unicamente o aumento de suas habilidades e o aprofundamento da sujeição, mas a formação de uma relação que no mesmo mecanismo o torna tanto mais obediente quanto é mais útil e vice-versa. A geriatria, presente neste contexto, se articula não apenas à disciplina-saber, mas também à disciplina-corpo. ${ }^{1}$ Os saberes especializados sobre e para os velhos são focados em um trabalho direto no corpo, com manipulações previstas nos seus gestos, nos seus comportamentos.

A prática médica instituída para a velhice fabrica corpos submissos, corpos "dóceis", que vão sendo constituídos ao longo dos tempos. Este é o primeiro efeito produzido pelas relações de poder oriundas da disciplina, que vão sendo responsáveis pela constituição de um saber permanente sobre

1 De acordo com Foucault (2009), a disciplina-saber refere-se ao investimento nos saberes sobre determinado campo dedicado a estudar o sujeito e suas relações. A disciplina-corpo refere-se ao investimento na utilidade e adestramento do corpo individual do sujeito 
o velho. Este sujeito vincula-se a determinado espaço e é acompanhado por um olhar contínuo, que visualiza sua evolução, sua cura, aquisição do seu saber etc.

Cabe citar aqui que os asilos e os hospitais são alguns desses espaços que, ainda, abrigam a população de velhos. Nestes lugares encontramos indivíduos sendo cuidados e tratados sob um olhar vigilante de uma equipe de saúde. Nas instituições asilares havia e ainda há uma preocupação com os velhos de forma singular, para que eles fossem/ sejam disciplinados e docilizados. Nos dias de hoje, até mesmo nestes espaços, o investimento se dá também pelo entendimento de que esses indivíduos, agora, são um grupo populacional, necessitando de um controle social que incide sobre o corpo-espécie, atrelando aquilo que Foucault (2008a, 2008b, 2010b) chamou de biopolítica, um investimento sobre a vida na coletividade. A constituição desta população passa, a partir da década de 60 e 70 do século XX, a ter uma visibilidade social e se tornar um problema coletivo.

De acordo com Debert (1999), a transformação da velhice em questão coletiva configura-se a partir da institucionalização generalizada das aposentadorias, em que, sobretudo o Estado, passa a se responsabilizar por um número maior de sujeitos e, ainda, pelas consequências econômicas dessa universalização dos sistemas de aposentadoria. Neste momento, vemos a criação de regulamentos e serviços próprios à velhice, em que o sistema hospitalar, a assistência e a seguridade social separam de vez o cuidado anteriormente destinado aos indigentes. $\mathrm{Na}$ esteira dos estudos foucaultianos, vemos aí a articulação de dois poderes potentes que fazem funcionar essa nova categoria etária: o poder disciplinar e o biopoder.

A fragmentação entre velhice e indigência, também fortalecida pela unificação dos discursos especializados, apresenta a noção de terceira idade. Substitui-se a ideia de isolamento, solidão, invalidez, por um espaço de lazer, complemento daquilo que não foi possível efetivar na juventude, de novas habilidades e hábitos. Vê-se criar uma espécie de "política da velhice", na qual o controle social dos velhos continua a operar sobre o corpo, através das práticas de saúde que também permanecem inseridas nesse processo de controle e disciplinamento.
A geriatria, nos dias de hoje, está disposta a disciplinar e esquadrinhar a vida humana em toda sua extensão. Cabe pensar aqui que as ações de promoção da saúde, instituídas para as mais variadas populações, estão postas como estratégias de captura dos corpos.

Nesse pensamento é oportuno descrever que inúmeras dessas ações de promoção iniciam não na "melhor idade" - como são apresentadas as pessoas com mais de 60 anos -, mas na menor idade, quando cuidados com uma boa alimentação dos infantis, com sua reduzida exposição ao sol ou até mesmo com grande incentivo de práticas regulares de atividade física estão sob os olhares atentos da ciência médica e do Estado. Prevenir doenças típicas da terceira idade como a osteoporose, a doença pulmonar obstrutiva crônica (DPOC), o câncer de pele ou outras tantas patologias que aparecem com o avançar da idade tem sido um desafio iniciado na família e/ou nos bancos escolares.

Em relação a essas questões, podemos refletir com Ortega (2008) quando ele nos diz que quanto mais jovens formos, quanto mais saudáveis parecermos, quanto mais cuidarmos de nossa saúde - ou seja, quanto mais regramos nossa existência pelos saberes e poderes da racionalidade médica ocidental -, mais seremos acolhidos socialmente. $\mathrm{O}$ autor ainda acrescenta que tudo o que é passível de ser vivido está submetido a um filtro moral, que disciplina os corpos e ordena cada um deles. Vemos, com isso, o convite para a construção de uma juventude eterna, que precisa ser permanentemente buscada.

Ampliando o olhar na história genealógica da velhice, percebemos a importância da emergência de diferentes documentos legais que se preocupam em dar visibilidade a essa população. Vale citar que, no Brasil, antes da década de 70 do século XX, os idosos recebiam, especialmente, atenção de ordem caritativa de instituições não governamentais, como as entidades filantrópicas e religiosas. Conforme Rodrigues (2001), os artigos do Código Civil (1916), do Código Penal (1940) e do Código Eleitoral (1965), além da Lei no 6.179, de 1974, que criou a Renda Mensal Vitalícia, são alguns destes documentos que abordaram a categoria etária em questão. Entretanto, as discussões sobre o processo de envelhecimento tomam como 
marco a primeira Assembleia Mundial sobre Envelhecimento, da Organização das Nações Unidas, ocorrida em 1982, na Áustria, onde participantes de vários países, incluindo o Brasil, reuniram-se para estudar e aprimorar questões sobre a velhice e estabeleceram o Plano de Ação Internacional para o Envelhecimento.

Nas discussões ocorridas nesse evento e, especialmente, no documento que apresenta esse Plano, fica evidente que todas as reflexões partem do reconhecimento de que há um aumento expressivo da população de velhos e que, por este motivo, precisam ser criadas, individualmente e coletivamente nas e pelas nações, estratégias que garantam a segurança econômica e social das pessoas com mais idade, além da apresentação de oportunidades para que estas pessoas sejam úteis e contribuam para o desenvolvimento de seus países.

Dentre as orientações para execução do Plano, destacamos o importante papel dos governos na identificação dos seus objetivos e prioridades, vistas as particularidades de cada sociedade, cultura ou região.

Uma importante função dos governos com relação ao Plano de Ação consiste em avaliar e examinar o processo de envelhecimento desde os pontos individuais e demográficos, para determinar suas consequências no desenvolvimento do seu país, à luz de sua situação política, social, cultural, religiosa e econômica. (ORGANIZAÇÃO DAS NAÇÕES UNIDAS, 1982, p. 42).

No Brasil, o reconhecimento desse Plano, como um importante documento para direcionar as estratégias com o olhar econômico, cultural e social, culminou com a inserção mais presente do idoso na Constituição Federal de 1988 e, mais tarde, com a aprovação da Lei n ${ }^{\circ} 8.842 / 1994$, que estabelece a Política Nacional do Idoso. Consolidando os direitos assegurados a esta população nesses dois documentos, temos, ainda, a criação do Estatuto do Idoso em 2004. Estes documentos, entendidos como uma ferramenta do Estado, são compostos por inúmeras regras e diretrizes, parte de um conjunto de práticas discursivas, ou seja, de um encontro de várias vozes, socialmente construídas, que falam da velhice, e ao falarem dela criam os sentidos pelos quais os sujeitos a reconhecem e se reconhecem como idosos.
O Estatuto hoje representa o principal documento de regulação dos idosos, já que funciona como um guia das ações do Estado e da sociedade civil para todos os processos de investimentos em prevenção e/ou tratamento dessa população. Podemos dizer que é o modelo de como a velhice é vista e significada na atualidade. E ainda, citando Foucault (2010a), é possível elucidar que este documento engloba ferramentas de controle da população, em que são apresentadas tecnologias que visam ao equilíbrio global.

Torna-se evidente que a implantação dessas políticas específicas para o idoso está diretamente relacionada às relações de saber-poder que se multiplicam a partir de vozes autorizadas - os geriatras, por exemplo - a determinar diretrizes e dar condições de possibilidade para constituição dessa população. O campo de saber da geriatria impulsiona o interesse do Estado e a produção de uma série de conhecimentos sobre a velhice. Podemos, ainda, como já sugerido anteriormente, enxergar a instituição de uma terceira idade, enquanto ideal de idoso saudável e ativo, como um modo de subjetivação, implementado através de um dispositivo saber-poder, em que especialistas da medicina geriátrica fazem valer o discurso de verdade $^{2}$ e prescrevem um modo de ser e existir para o idoso.

O velho, nessa relação de poder e de saber, dispõe de um corpo alvo de controle de uma ciência à qual se atribui a meta de prolongar a vida, evitando a morte. Os profissionais do saber arvoram-se, muitas vezes, em condutores do modo de se viver, instituindo nos viventes a cultura pelos malefícios que venham a sofrer. $\mathrm{Na}$ pretensão de dirigir a vida, controlando o seu processo, com o intuito de melhorá-la, multiplicam-se as prescrições a serem seguidas como modelos gerais (TÓTORA, 2006).

$\mathrm{O}$ que nos é descrito pela autora reforça o entrelaçamento entre as estratégias disciplinares e os mecanismos de segurança pensados para a população de idosos. Os saberes produzidos pelos especialistas auxiliam fortemente na condução de formas de viver que colocam o sujeito como alvo

2 Entendemos o conceito de verdade a partir de Foucault (2010a). A verdade é uma produção discursiva. Sendo assim, entendemos a medicina geriátrica como potente ferramenta que constitui e legitima verdades através de seus saberes. 
de políticas econômicas e sociais. É desta e por esta forma que a geriatria se constitui como uma condição de possibilidade para emergência da população de idosos. É esta ciência proposta por especialistas, atrelada a documentos oficiais, que produz verdades sobre os idosos, que dá vez e voz à população de velhos.

Diante disso, fizemos a escolha de um material empírico que vem fortemente constituindo verdades e determinando formas de vida, pautadas, muitas vezes, nos saberes produzidos pelos especialistas. Na próxima seção serão apresentadas algumas reportagens de dois jornais gaúchos, que abordam o tema envelhecimento.

\section{Verdades fabricadas sobre Envelhecimento na mídia impressa}

$\mathrm{Na}$ busca por pensar nas enunciações midiáticas acerca do envelhecimento na atualidade, buscamos colocar em funcionamento algumas ferramentas da análise discursiva. Como foi dito no início deste artigo, queremos trazer à tona situações, atitudes e ações que são anunciadas por especialistas para serem seguidas por um número expressivo de pessoas a fim de alcançar a "melhor idade" com qualidade de vida. Para isso, utilizamos a mídia, a partir de algumas reportagens de capa dos cadernos de saúde de dois conceituados jornais, como um dispositivo pedagógico. Esse dispositivo, apresentado por Fischer (1996), é entendido como uma ferramenta de constituição de sujeitos e subjetividades, a partir da produção de saberes que de alguma forma conduzem as pessoas a determinadas formas de ser e viver na sociedade contemporânea.

Um dos cadernos de saúde analisado é o Viva Bem, do Diário Popular, com edições semanais, levadas a milhares de pessoas do sul do Rio Grande do Sul. O outro é chamado Caderno Vida, que integra todos os sábados o Jornal Zero Hora, produzido na capital do Rio Grande do Sul, com mais de 180 mil exemplares distribuídos diariamente. Em ambos os materiais de estudo encontramos reportagens focadas na área da saúde, com discussões atuais apresentadas, na maioria das vezes, por especialistas.
$\mathrm{Na}$ tentativa de encontrar fragmentos, cenas, episódios que permitam esse olhar sobre o envelhecimento, buscamos reportagens que trazem as enunciações da velhice no período de 2004 a 2010, uma vez que é dada grande visibilidade a esta população a partir de 2004, ano que foi instituído o Estatuto do Idoso. É a partir de uma análise teórica com material empírico de sete anos que pretendemos apresentar as enunciações produzidas nestes materiais impressos.

Cabe destacar, ainda, em termos de escolhas para esta pesquisa, que o uso desses jornais como fonte de análise é por acreditarmos que a mídia na atualidade é parte integrante de nossas vidas, uma vez que participa da construção e educa os sujeitos. De acordo com Gomes (2003), o jornalismo interfere na modelização social, pois disponibiliza espaços por onde os discursos têm seu ponto máximo de difusão. Complementa a autora: “[...] ficará fácil compreender que onde quer que haja discurso há palavras de ordem, a disciplina e o controle com que ele alimenta, e dos quais se alimenta. Por todo espaço, a todo tempo, enuncia-se o visível e, portanto, o vivível" (GOMES, 2003, p. 103).

A mídia, por sua vez, apresenta aquilo que deve ser dito, indicando a forma como deve ser dito, para que seja utilizado como guia, como um manual de orientações capaz de adestrar os sujeitos ao longo de suas vidas. É este, como diz Hara (2007), o primado da comunicação: minuto a minuto ela molda nossa subjetividade com os ideais da massa ao nos convidar a participar, ao nos persuadir a jogar.

Acompanhada dessa problematização teórica iniciamos a análise dos dados, querendo dar visibilidade às formas de ser e viver a velhice na atualidade. Com isso, queremos evidenciar o quanto uma velhice pautada no tratamento e na cura das doenças vem sendo esvaziada de significados e vem tomando força um envelhecimento marcado pela prevenção e cuidado com o corpo. A gestão da velhice, que durante algum tempo esteve sob a guarda da família e do indivíduo, com foco primordial nos processos patológicos, transforma-se, agora, em uma questão de esfera pública, cujo foco primordial é a promoção da saúde.

A ampliação do conceito de saúde pautada não mais pela ausência da doença, mas, sim, por um bem-estar físico, emocional, social e espiritual faz 
com que a prática diária dos idosos esteja focada em ações de prolongamento da vida. São estas ações que iniciamos agora a apresentar. $\mathrm{Na}$ reportagem intitulada Em busca da felicidade, matéria de capa do caderno Viva Bem, somos convidados a refletir sobre um velho-saudável, da atualidade, quando lemos que o progresso da medicina nos permite viver mais e com mais saúde, podemos nos alimentar bem, podemos nos defender do calor e do frio com meios sofisticados, enfim, gozamos de uma série de regalias que eram impensáveis aos nossos bisavós ${ }^{3}$ (EM BUSCA..., 2004, p. 1).

Indo ao encontro desse velho atual, também destacamos duas reportagens do caderno Vida do Jornal Zero Hora. Uma produzida especialmente para a milésima edição deste conceituado caderno, O que será do Homem (O QUE..., 2010, p. 1), que evidencia a longevidade como fio condutor, apresentando uma reportagem dedicada à saúde do futuro, que será revolucionada pela prevenção, promoção da saúde e o tratamento de doenças.

Avanços da medicina vão dominar doenças hoje incuráveis e ajudar a estender ainda mais a expectativa de vida do homem. A engenharia genética já é capaz de selecionar embriões e dar continuidade apenas à gestação de bebês saudáveis. Pesquisas em células-tronco e o estudo de medicamentos inteligentes apontam uma esperança de cura para doenças como o câncer. Vacinas para prevenir o HIV estão em fase final de estudo. Todas essas novidades fazem parte de um conjunto de avanços da ciência que ao longo dos anos vêm propiciando uma vida mais longa ao homem. Como reflexo dessa revolução médica, nas últimas cinco décadas houve um aumento de $600 \%$ no contingente de idosos no Brasil, conforme dados do IBGE. Os homens da época Medieval, por exemplo, eram considerados velhos aos 30 anos. Nos anos 2000, um indivíduo de 80 vai à academia, faz caminhadas, dança e dá um baile em muitos mocinhos. Generosas, as projeções apontam uma expectativa de vida de 85 anos em 2025, e não será nada surpreendente pessoas chegando aos 120 por volta de 2050. Essa reviravolta na área médica já era premonitória há quase duas décadas. (O QUE..., 2010, p. 3).

A segunda reportagem do Caderno Vida, que também faz referência às condutas que devemos

3 Para distinguir das citações diretas dos autores, os excertos do material empírico estarão em itálico. ter para nos tornarmos um velho com saúde, tem como título Prepare-se bem para a terceira idade (PREPARE-SE..., 2009, p. 1). Nesta matéria o leitor encontra algumas estratégias de adestramento para o corpo saudável, como a prática regular de exercícios, o tipo de alimentação saudável.

Com a prática regular de exercícios físicos, o indivíduo emagrece, aumenta a sua força muscular, melhora a sua capacidade respiratória e, consequentemente, previne ou controla diversas doenças. Sozinha, a atividade física não garante a longevidade, mas certamente fortalece o organismo e colabora para elevar a expectativa média de vida de uma população. A prática de atividades físicas com comprometimento é essencial para a longevidade e para melhorar a qualidade de vida - defende o médico.

Percebemos nessas enunciações um tipo de poder que cada vez mais intervém para fazer viver, que intervém na forma e na maneira de viver, com o foco de aumentar a vida. Este poder, descrito por Foucault, está centrado na vida.

É uma tecnologia que agrupa os efeitos de massas próprios de uma população, que procura controlar a série de eventos fortuitos que podem ocorrer numa massa viva... [...] É uma tecnologia que visa, portanto, não o treinamento individual, mas, pelo equilíbrio global, algo como uma homeostase: a segurança do conjunto em relação aos seus perigos internos. (FOUCAULT, 2010b, p. 209).

É o biopoder que, a partir do final do século XVIII, atua como mecanismo de intervenção na condução de uma população, aqui a população de velhos. Este poder de regulamentação tem produzido inúmeras reflexões que perpassam os interesses políticos, midiáticos e mercadológicos acerca do "novo velho", que são justificados em alguns movimentos na história do país e na própria criação do Estatuto do Idoso.

Outras enunciações que apresentam esse foco do poder centrado na vida, capaz de agrupar os efeitos próprios de uma população, estão apresentados para os milhares de idosos, adultos e jovens através das mídias impressas escolhidas no estudo. Citamos aqui a fala de Foucault (2010b) que expressa a velhice como uma das áreas de intervenção da biopolítica. 
De que se trata nessa nova tecnologia do poder, nessa biopolítica, nesse biopoder que está se instalando? Eu lhes dizia em duas palavras agora há pouco: trata-se de um conjunto de processos como a produção dos nascimentos, dos óbitos, a taxa de reprodução, a fecundidade de uma população, etc. São esses processos de natalidade, de mortalidade, de longevidade que, justamente na segunda metade do século XVIII, juntamente com uma porção de problemas econômicos e políticos (os quais não retomo agora), constituíram, acho eu, os principais objetos de saber e os primeiros alvos de controle dessa biopolítica. (FOUCAULT, 2010b, p. 204).

Os alarmantes dados demográficos que projetam a aceleração do envelhecimento da população, com trágicas consequências no setor econômico, são responsáveis pelo recente despertar da sociedade brasileira em relação às condições de vida dos idosos e aos lugares destinados a eles no cenário social. Em se tratando de condições de vida e novos espaços para habitação dessa população, basta olhar para os nossos familiares com mais idade e reconhecer neles utensílios de uso diário. Vejamos alguns: sapatos confortáveis, fáceis de calçar e ainda modernos; cremes de uso contínuo, com fator de proteção para exposição solar; diálogos de participação em bailes para terceira idade ou até mesmo planejamento de uma viagem. Não há dúvida, o modo de encarar a velhice mudou.

O envelhecimento constitui-se de outro modo nas sociedades contemporâneas. O idoso encontra-se mais isento de conotações depreciativas e se sente pronto para atender os interesses de um mercado de consumo emergente, que se prepara, especialmente, com atividades de lazer e de saúde capazes de satisfazer esta população. Há uma modificação no cenário, onde a improdutividade decorrente do tempo de trabalho e apresentada pela aposentadoria é modificada pela inserção do velho no mundo do consumo, o que o torna novamente útil para a sociedade. A única velhice acolhida no presente parece ser aquela vinculada diretamente à saúde, à jovialidade e à produtividade, obtidas mediante o cumprimento de uma agenda sanitária que engloba medicamentos adequados, exercícios corretos e o consumo de tudo quanto potencialize a juventude eterna.
Dóceis e úteis, esses cidadãos são capturados por serviços e produtos de todos os tipos, como grupos de atividades físicas, de turismo, universidades para terceira idade, praças públicas com diversos equipamentos destinados à "melhor idade", cosméticos exclusivos para esta faixa etária, vestuário específico, cirurgias plásticas. Implicados nestes discursos dominantes, os idosos viram o jogo e são agora criados investimentos biopolíticos para o controle social desta população.

Na reportagem do Caderno Viva Bem (É PROIBIDO..., 2004, p. 1) É proibido envelhecer, exemplificamos esse convite ao mundo do consumo, uma aproximação com a juventude, capaz de mostrar maneiras de produzir o velho-jovem.

Envelhecer sem perder a juventude e sem precisar se submeter a uma cirurgia plástica é um desejo antigo da humanidade e que faz a indústria da estética faturar cada vez mais alto em todo mundo. M. S. (médico) oferece em sua clínica muitos tratamentos - invasivos ou não... [...] Diz o médico: - a ciência da beleza obteve progressos memoráveis que estão ao nosso alcance com custos nada absurdos. (É PROIBIDO..., 2004, p. 1).

Muitas outras enunciações reportam-se a esse convite, relacionando sempre a busca constante pela longevidade. Substâncias para rejuvenescimento (SUBSTÂNCIAS..., 2004, p. 1), Antibiótico natural (ANTIBIÓTICO..., 2004, p. 1), A ginástica I Qi Gong (A GINÁSTICA..., 2005, p. 1), Entre 2011 com novos hábitos (ENTRE 2011..., 2010, p. 1), evidenciam a ênfase em cuidados preventivos para o indivíduo viver bem tanto fisicamente quanto emocionalmente e garantir o não aparecimento de doenças com o avançar da idade. Com tais enunciações, os jornais vão educando para um controle cotidiano das ações de determinada população, normalizando a vida em toda sua extensão.

No contexto descrito, cabe apresentar a discussão de norma feita por Foucault (2010b), no sentido de que esta pode se aplicar tanto a um corpo que se quer disciplinar, quanto a uma população que se quer regulamentar. Trazemos à tona o conceito de sociedade de normalização que para o autor

[...] é uma sociedade em que se cruzam, conforme uma articulação ortogonal, a norma da disciplina e a norma da regulamentação. Dizer que o poder, no século XIX, tomou posse da vida, dizer pelo menos 
que o poder, no século XIX, incumbiu-se da vida, é dizer que ele conseguiu cobrir toda a superfície que se estende do orgânico ao biológico, do corpo à população, mediante o jogo duplo das tecnologias de disciplina, de uma parte, e das tecnologias de regulamentação, de outra. (FOUCAULT, 2010b, p. 213).

Podemos dizer que muitas são as táticas de regulamentação para população de idosos, que os normalizam. Há assim uma concepção de idoso normal e de um "possível" velho anormal, patológico, construído através de critérios que são definidos por um conjunto de saber, neste caso a geriatria. Com isso, vemos o quanto os saberes nada têm de neutros. Muito pelo contrário, estão marcados por poderes que, em uma relação de forças, de saber e poder, produzem e determinam formas de vida. Em todas as ações projetadas hoje para o corpo do velho percebemos uma grande vontade de trazê-los para a zona de normalização. ${ }^{4}$

Um exemplo bastante claro do quanto os idosos, nos dias de hoje, são convidados para fazer parte de uma sociedade de normalização está explicitado no site do Ministério da Saúde, quando descreve:

A proposta de envelhecimento ativo e saudável busca oferecer qualidade de vida por meio da alimentação adequada e balanceada, prática regular de exercícios físicos, convivência social estimulante, diminuição dos danos decorrentes do consumo de álcool e tabaco e diminuição significativa da automedicação. O idoso saudável tem sua autonomia preservada, tanto a independência física, como a psíquica. (BRASIL, 2013).

Nesse convite fica evidente que o trabalho do Estado é baseado na promoção de um envelhecimento ativo e saudável, capaz de normalizar essa população. É preciso referir que a partir do referencial foucaultiano (FOUCAULT, 2001, 2009), o poder não é da ordem da repressão, mas é entendido como produtivo. $\mathrm{O}$ autor também reforça que foi a partir das disciplinas e da normalização que este tipo de poder passa a funcionar vinculado diretamente a um saber.

A geriatria, ciência apresentada neste estudo, deve ser considerada como uma das condições

\footnotetext{
4 Para François Ewald (1993), embasado em Foucault, todos estão na norma, porém há alguns que se encontram na zona de normalização e outros que estão à margem desta zona. É com afinco que as estratégias de poder investem nos ditos anormais para cada vez mais trazê-los para esta zona e então podermos chamá-los de "normais".
}

de possibilidade para colocar em funcionamento esse novo tipo de poder, seja através dos inúmeros efeitos que ela produz, ou até mesmo pelo próprio conhecimento científico produzido para o corpo envelhecido. Estamos falando aqui de idosos adestrados que estão expostos a um controle permanente, conduzindo suas ações para aquilo que convencionamos chamar de um "envelhecimento saudável". "A disciplina normaliza, e creio que isso é algo que não pode ser contestado" (FOUCAULT, 2008b, p. 74).

Refletindo sobre o processo de envelhecimento, fica evidente a produção de outro sujeito, prescrito pela sociedade de normalização. Vale dizer aqui que para este novo modelo é necessário a criação de saberes, determinando modos de vida. Para deixar mais claro, podemos dizer que, no processo de normalização disciplinar, o que importa é a norma, aquilo que é estabelecido como norma, e só a partir disso que se determina quem é o normal e o anormal. É por este motivo que Foucault (2008b) traz o conceito de normação, uma vez que no processo de normalização disciplinar partimos da norma.

Dito isso, precisamos trazer essa conceituação para os dias de hoje, quando não basta para os idosos, enquanto uma população, apenas dar seguimento às condutas de um ser saudável e ativo, e sim, precisa ser acrescentado a isso estratégias e técnicas de regulamentação dessas pessoas com mais idade. A discussão da norma aqui extrapola sua localização em arquiteturas e instituições e alcança a necessidade de gestão da população de velhos. Assim é que na sociedade marcada pelo biopoder não partimos da norma, mas do normal. A partir dos estudos da normalidade, fixamos aquilo que, num dado momento, é atribuído como normal (FOUCAULT, 2008b). Estamos falando de uma gestão acionada por estratégias governamentais, que definem formas, práticas e maneiras de se ter um velho-saudável. Citamos aqui os investimentos atuais feitos em espaços públicos destinados ao acolhimento de pessoas na "melhor idade", onde equipamentos para realização da atividade física estão à disposição desta população. Cabe ainda ressaltar as inúmeras apresentações trazidas por profissionais do mundo arquitetônico para o cotidiano do lar do idoso. São projeções com aberturas mais espaçosas, com menos irregularidades, apoios 
de segurança, entre tantas outras táticas e estratégias para garantia de um viver mais e melhor neste estágio da vida.

São muitas as formas de explicitar as estratégias de regulamentação que, no nível biopolítico, normalizam uma população. E é diante deste entendimento que sugerimos revisitar as discussões de caso, risco, perigo e crise apresentadas por Michel Foucault na aula de 25 de janeiro de 1978 no Collège de France, descrita no livro Segurança, Território, População, a fim de aprofundar o entendimento que a emergência destas novas noções nos trazem para as reflexões que aqui fizemos.

A discussão, a partir desses quatro elementos dos dispositivos de segurança, nos coloca a pensar sobre a gestão que é realizada atualmente para e sobre os idosos. Há muitas formas de apresentar e refletir sobre isso. Refletir como hoje os velhos são normalizados. Trazemos uma para apreciação: de conhecimento global, a Influenza, mais conhecida como H1N1 ou gripe A, tem sido motivo de grandes investimentos governamentais. Foi a partir da identificação de casos desta patologia, da mensuração dos riscos em que a população em geral estava exposta, da quantificação e da qualificação do processo, a ponto de dizer que os idosos eram indivíduos vulneráveis em termos de exposição, e ainda da verificação de uma proliferação mundial da patologia, descrevendo uma situação de crise, que se tornou evidente a necessidade do aparecimento de mecanismos de segurança apoiados aos já existentes, os disciplinares, para dar condições de continuidade da existência dessa população.

Partindo do exemplo da gripe H1N1, podemos dizer que depois de instaurada e controlada a crise, conseguiu-se aprofundar os conhecimentos sobre esta patologia e determinar o que seria esperado para os próximos tempos em termos de morbidade e mortalidade, ou seja, as estatísticas apresentaram aquilo que seria normalmente esperado desta doença para determinados grupos populacionais. Ainda pela classificação de faixa etária e do estado imunológico, foi possível produzir diferentes curvas consideradas normais. Citamos os próprios idosos, as gestantes, as crianças com menos de dois anos de idade, grupos estes que, em determinado momento de crise, foram considerados de risco, e para prevenção dos mesmos foi necessário criar mecanismos de controle para reduzi-los ao estado de normalidade global.

Verificamos, por esse exemplo, que os dispositivos de segurança se constituem diante das necessidades apresentadas por uma determinada população, no intuito de trazê-la para a norma, de controlá-la. Fica evidente que o que estava posto em termos de uma sociedade de normalização da disciplina não dá conta do que hoje a população de velhos necessita para um envelhecimento saudável, de todo investimento que precisa ser feito para que tenham acesso às condições que circundam e determinam esse processo de viver mais e viver melhor. Para deixar ainda mais claro, buscamos, nas palavras de Foucault (2008b), a diferenciação clara entre a sociedade de normalização da disciplina e a discutida nos dias de hoje, em um tempo de biopolíticas:

Nas disciplinas, partia-se de uma norma e era em relação ao adestramento efetuado pela norma que era possível distinguir depois o normal do anormal. Aqui, ao contrário, vamos ter uma identificação do normal e do anormal, vamos ter uma identificação das diferentes curvas de normalidade, e a operação de normalização vai consistir em fazer essas diferentes distribuições de normalidade funcionarem umas em relação às outras e [em] fazer de sorte que as mais desfavoráves sejam trazidas às que são mais favoráveis. Temos, portanto, aqui uma coisa que parte do normal e que se serve de certas distribuições consideradas, digamos assim, mais normais que as outras, mais favoráveis em todo caso que as outras. A norma está em jogo no interior das normalidades diferenciais. O normal é que é primeiro, e a norma se deduz dele, ou é a partir desse estudo das normalidades que a norma se fixa e desempenha seu papel operatório. Logo, eu diria que não se trata mais de uma normação, mas sim, no sentido estrito, de uma normalização. (FOUCAULT, 2008b, p. 82).

A partir desses estudos podemos verificar que a reportagem Ponte para a qualidade de vida, apresentada no Caderno Viva Bem (PONTE..., 2009, p. 1-2), coloca em funcionamento a aproximação de uma determinada população a uma zona de normalização, uma vez que, já no início da reportagem, é apresentado o número atual e futuro de participantes de um grupo de fisioterapia preventiva para indivíduos com Parkinson e, ainda, a intenção de trazer os idosos com esta patologia para uma 
inserção mais ativa na sociedade, na busca pelo "envelhecer saudável". Com a idade em torno dos 60 anos, portadores do Mal de Parkinson descobriram a chance de vencer os obstáculos da doença, buscando qualidade de vida e interação social.

No decorrer dessa matéria, temos também a fala da esposa de um idoso parkinsoniano que mostra todo seu empenho em construir espaços de discussão e convivência para estes sujeitos vivenciarem de forma mais tranquila a doença.

Na mesma linha produzida por essa reportagem, podemos olhar para a temática do tabagismo, discutida muitas vezes nas reportagens. Está posto para a sociedade que o cigarro provoca uma quantidade expressiva de doenças na população, especialmente nos idosos. Foi com o objetivo de mostrar ao ser humano os malefícios causados pelo tabaco que muitas dessas reportagens foram produzidas. Trazemos aqui algumas destas publicações: $U m$ alerta às mulheres (UM ALERTA..., 2010, p. 1), Recorde a favor da saúde (RECORDE..., 2009, p. 1), Dia de combate a DPOC (DIA..., 2009, p. 1) e Uma doença incapacitante (UMA DOENÇA..., 2010, p. 1).

Na primeira é apresentada a problemática social e econômica que o cigarro traz nos dias de hoje. De acordo com as estimativas da Organização Mundial da Saúde (OMS) há um bilhão de fumantes no planeta (UM ALERTA..., 2010, p. 1) Com esta afirmação complementada ainda nessa matéria, pelos resultados de um estudo feito pela OMS, a pesquisa revelou também dados preocupantes sobre os danos causados pela dependência de nicotina. Se o quadro atual persistir, em 2030 o número de mortes causadas pelo cigarro e seus derivados deve pular para 8 milhões; vemos a interlocução com o que está apresentado na terceira e quarta publicações, nas quais o foco é dizer à comunidade em geral que o tabaco é o principal causador da DPOC. Outra medida de suma importância é que a população atente às campanhas antitabagistas, já que a maior parte dos casos de DPOC - entre 80 e $85 \%$ - está relacionada ao cigarro e, portanto, poderá ser evitada (DIA..., 2009, p. 1).

Continuando o diálogo do tema tabagismo, percebemos na reportagem Recorde a favor da Vida, já citada anteriormente, o relato de um aposentado que comemora os 30 anos longe do cigarro. Em 11 de maio de 1979, Volmar trocou o vício pela saúde, depois de 12 anos fumando em média um maço por dia. Na avaliação dos benefícios para a saúde diante da escolha feita pelo aposentado, podemos visualizar a fala do médico:

A troca é por saúde, como fez Volmar, ao abandonar um hábito que pode trazer 26 enfermidades fatais, dentre elas 11 tipos de câncer. Perto de completar 60 anos, Volmar joga futebol de sete semanalmente com três grupos diferentes, faz caminhadas na esteira de casa. Paladar e olfato ganharam em qualidade e, fisicamente, o aposentado aparenta ter dez anos menos. (RECORDE..., 2009, p. 1).

Assim como na enunciação sobre os indivíduos com Parkinson e a aproximação com a realidade social, nas apresentadas sobre tabagismo e DPOC, fica evidente a preocupação de trazer todas as pessoas para um controle maior. Olhando para esta necessidade de ter todos sobre o mesmo foco, podemos citar Foucault (2001, p. 62): “[...] a norma não tem por função excluir, rejeitar. Ao contrário, ela está sempre ligada a uma técnica positiva de intervenção e de transformação, a uma espécie de poder normativo."

Dessa forma, podemos mencionar que nossa sociedade constitui-se naquilo que Foucault anunciou como uma sociedade de normalização. A partir do século XVIII é que percebemos todo um investimento nas populações, a fim de se tornar meta final do governo. Na discussão aqui apresentada, reforçamos que o investimento na população de idosos está presente desde a infância, na qual a criança, conduzida por hábitos adequados, se torna a grande responsável pelas modificações estatísticas que envolvem a redução da mortalidade, dos casos de doença e, consequentemente, a garantia de uma vida melhor e mais longa.

Pensar que, tanto nas reportagens que tratavam de hábitos e ações adequadas para se realizar ao longo da vida, quanto nas que explicitaram as táticas e estratégias para uma aproximação com a juventude, é perceber que ao dar visibilidade ao ser e viver a velhice na atualidade, a mídia impressa retrata a busca constante pela longevidade. Mostra, para uma população específica, a maneira de viver e levar a vida nos dias de hoje. 


\section{Considerações finais}

Ao colocarmos ponto final neste artigo, muitas questões, certamente, ainda nos passam e nos produzem uma sensação de estranheza. Escolher a velhice como temática de investigação e analisar na mídia impressa a forte modelagem descrita para esta população, no mínimo, continuará nos causando inquietação.

Vale referir que o que está em jogo neste texto não é um posicionamento favorável ou contrário a todas essas intervenções de promoção de saúde evidenciadas por especialistas ou garantidas em documentos legais para construção de um envelhecimento melhor, nem mesmo a intenção de propor uma nova forma de dizer ou fazer isso. Nosso propósito é, isto sim, possibilitar um tipo de problematização ao ver e/ou falar sobre a velhice.

Tentar olhar para a História e perceber a constituição da população de idosos foi o que propomos desde o início. Através, especialmente, da criação, no início do século XX, da geriatria, é que conseguimos contar uma história, selecionando alguns de seus acontecimentos. No decorrer dos tempos, dadas as condições de possibilidade do ingresso dos velhos em legislações e ainda a criação de regulamentos específicos para esta população, foram precisos outros investimentos além do disciplinamento individual de cada corpo envelhecido. Foi necessária uma modificação nas relações de poder englobando os mecanismos de regulamentação, tão utilizados na atualidade.

Esses mecanismos foram apresentados no decorrer das reportagens analisadas, em que se evidenciou uma velhice pautada pela promoção da saúde, isto é, um envelhecimento saudável. As enunciações de promoção adotadas atualmente, que enquadra todos os sujeitos como passíveis de intervenção, mostra-nos o projeto determinado pela geriatria, que direciona o controle da vida humana em toda sua extensão. A promoção da saúde hegemônica atual pode ser interpretada como uma política de neo-higiene interna, de forte conteúdo moral com vistas à longevidade (CASTIEL; DIAZ, 2007). A constituição desta nova figura do velho está pautada na necessidade de adaptação desta população para acompanhar o acelerado fluxo de acontecimentos que marcam a nossa época.

Podemos pensar, a partir dos estudos desses autores, que a emergência da terceira idade nos coloca no movimento de problematizar as ações de educação em saúde para esta população, refletindo sobre todo o investimento feito em estratégias de prevenção para que a vida seja cada vez mais longa e melhor.

Parece-nos que, ser provocados por alguns fragmentos do percurso histórico da velhice e, ainda, pelo produto de análise escolhido para este artigo abala nossas certezas sobre esse grupo populacional. Olhá-lo, entendendo-o como grupo descontinuísta e marcado por discursos que compõem as verdades de cada época, é o convite que nos deixou Foucault. Quem sabe com essa história provocativa que aqui escrevemos, possamos responder, minimamente, como nos tornamos aquilo que somos enquanto sujeitos de saber e sujeitos de poder na atualidade, provocando nosso pensamento a discutir a história diferente do que se pensa e tornar-se diferente do que se é.

\section{REFERÊNCIAS}

A GINÁSTICA I Qi Gong. Diário Popular, Pelotas, 18 jan. 2005. Viva Bem, p. 1-2.

ANTIBIÓTICO natural. Diário Popular, Pelotas, 28 dez. 2004. Viva Bem, p. 1-3.

BRASIL. Ministério da Saúde. Saúde do Idoso - apresentação. Brasília, 2013. Disponível em: <http://portal.saude. gov.br/portal/saude/visualizar_texto.cfm?idtxt=26466>. Acesso em: 10 mar. 2013.

CASTIEL, Luis David; DIAZ, Carlos Álvarez-Dardet. A saúde persecutória: os limites da responsabilidade. Rio de Janeiro: Fiocruz, 2007.

DEBERT, Guita. A reinvenção da velhice: socialização e processos de reprivatização do envelhecimento. São Paulo: Fapesp, 1999.

DIA de combate à DPOC. Diário Popular, Pelotas, 17 nov. 2009. Viva Bem, p. 1-2. 
É PROIBIDO envelhecer. Diário Popular, Pelotas, 26 out. 2004. Viva Bem, p. 1-2.

EM BUSCA da felicidade. Diário Popular, Pelotas, 13 jan. 2004. Viva Bem, p. 1.

ENTRE 2011 com novos hábitos. Zero Hora, Porto Alegre, 24 dez. 2010. Vida, p. 1-4.

EWALD, Francois. Foucault, a norma e o direito. Lisboa: Veja, 1993.

FISCHER, Rosa Maria Bueno. O dispositivo pedagógico da mídia: modos de educar na (e pela) TV. Educação e Pesquisa, São Paulo, v. 28, n. 1, p. 151-162, jan./jun. 2002.

FOUCAULT, Michel. Os anormais. São Paulo: Martins Fontes, 2001.

Nascimento da biopolítica. São Paulo: Martins Fontes, 2008a.

Segurança, território, população. São Paulo: Martins Fontes, 2008b.

Vigiar e punir: história da violência nas prisões. 37. ed. Petrópolis, RJ: Vozes, 2009.

Microfísica do poder. 9. ed. Rio de Janeiro: Graal, 2010a.

Em defesa da sociedade. 2. ed. São Paulo: Martins Fontes, 2010 b.

O nascimento da clínica. 7. ed. Rio de Janeiro: Forense Universitária, 2011.

GOMES, Mayra Rodrigues. Poder no jornalismo: discorrer, disciplinar, controlar. São Paulo: Hacker/Edusp, 2003.

HABER, Carole. Geriatrics: a specialty in search of specialists. In: TASSEL, David Van et al. Old age in a bureaucocratic society. Nova York: Greenwood Press, 1986. p. 66-84.

HARA, Tony. Sociedade da comunicação: controle e captura da singularidade. In: Revista Aulas - Dossiê Foucault, São Paulo, n. 3, p. 3-15, mar. 2007.

O QUE será do homem. Zero Hora, Porto Alegre, 31 dez. 2010. Vida, p. 1-3.

ORGANIZAÇÃO DAS NAÇÕES UNIDAS (ONU). Plano de Ação Internacional de Viena sobre o Envelhecimento. Estados Unidos, 1982. Disponível em: <http://www.un.org/en/development/devagenda/ageing.shtml > Acesso em: 10 abr. 2013.

ORTEGA, Francisco. O corpo incerto. Rio de Janeiro: Garamond, 2008.

PAPALÉO-NETTO, Matheus. Envelhecimento: desafio na transição do século. In: PAPALÉO-NETTO, Matheus. Et al. Gerontologia - a velhice e o envelhecimento em visão globalizada. São Paulo: Atheneu, 1996. p. 3-12.

PONTE para a qualidade de vida. Zero Hora, Porto Alegre, 7 abr. 2009. Vida, p. 1-3.

PREPARE-SE bem para a terceira idade. Zero Hora, Porto Alegre, 13 jan. 2009. Vida, p. 1-4.

RECORDE a favor da saúde. Diário Popular, Pelotas, 2 jun. 2009. Viva Bem, p. 1.

RODRIGUES, Nara. Política Nacional do Idoso: retrospectiva histórica. Estudos Interdisciplinares sobre o Envelhecimento, Porto Alegre, v. 3, p.149-58, 2001.

SILVA, Luna Rodrigues Freitas. Da velhice à terceira idade: o percurso histórico das identidades atreladas ao processo de envelhecimento. História, Ciências, Saúde-Manguinhos, Rio de Janeiro, v. 15, n. 1, p. 155-168, jan./mar. 2008.

SUBSTÂNCIAS para rejuvenescimento. Diário Popular, Pelotas, 12 out. 2004. Viva Bem, p. 1-2.

TÓTORA, Silvana. Ética da vida e o envelhecimento. In: CÔRTE, Beltrina; MERCADANTE, Elisabeth Frohlich; ARCURI, Irene Gaeta. (Org.). Envelhecimento e velhice: um guia para a vida. São Paulo: Vetor, 2006. p. 26-47.

UM ALERTA às mulheres. Zero Hora, Porto Alegre, 31 mai. 2010. Vida, p. 1-3.

UMA DOENÇA incapacitante. Zero Hora, Porto Alegre, 27 mar. 2010. Vida, p. 1-3.

Recebido em: 30.05 .2014

Aprovado em: 30.08 .2014 